\title{
Rural-Urban Migrate Decision of High Value Agricultural Products Growers in Northwest China
}

\author{
Lijia Wang', Xuexi Huo ${ }^{2}$, * \\ ${ }^{1}$ State Key Laboratory of Grassland Agro-Ecosystems, College of Pastoral Agricultural Science and Technology, Lanzhou University, Lanzhou, \\ China \\ ${ }^{2}$ College of Economics and Management, Northwest A \& F University, Yangling, Shaanxi, China
}

Email address:

wanglijia@1zu.edu.cn (Lijia Wang), xuexihuo@nwafu.edu.cn (Xuexi Huo)

\section{To cite this article:}

Lijia Wang, Xuexi Huo. Rural-Urban Migrate Decision of High Value Agricultural Products Growers in Northwest China. International Journal of Economic Behavior and Organization. Vol. 4, No. 1, 2016, pp. 1-7. doi: 10.11648/j.ijebo.20160401.11

\begin{abstract}
The paper explores determinants on rural labor's migration decision in Shaanxi province in northwest China. It adopts Probit regression and takes High Value Agricultural Products growers as an example. The econometric results suggest that great net family farm income and shift opportunity cost, rich farm experience, as well as large farm size mitigate grower's migration attitude, whereas poor rural infrastructure constructions and unclearly agricultural subsidy policies increase grower's willingness-to-transfer. Policy suggestions on enlarging family farm land holdings, targeting extension training at the older growers, improving telecommunications infrastructure and specifying agri-subsidy program are highly recommended.
\end{abstract}

Keywords: China, Grower, High Value Agricultural Products (HVAPs), Rural-Urban Migrate Decision

\section{Introduction}

An unprecedented rural-urban labor migration has occurred in China since the late 1980s. The employment population of urban labor force was dramatically keeping rising from 231.5 million to 382.4 million in period 2000-13, whereas the employment population in rural areas was decreased from 489.8 million to 387.3 million persons in the same period (source: China Statistical Yearbook 2014, National Bureau of Statistics of People's Republic of China). The increase of the number of urban employed persons can be partly attributed to the development of urbanization.

The speedily urbanization results in several adversely influences on the development of non-agricultural industries and the situation of agricultural production in China. Different from farm households in developed countries, i.e., the United States, averagely only 2.8 labors per farm household, including the minors and the elders, in rural areas work on farm activities in China, the young labors particularly works on off-farm activities locally and/or regionally [1]. This, consequently, leads to an insufficiency of farm labor in extensive agriculture which mainly uses small inputs of labor, fertilizers, and capital, relative to the land area being farmed, and followed by much lower yields. Parallel, the lower yield and agricultural incomes promote rural labor to migrate to urban jobs to compensate the family expenditure. Workers have shifted from rural to urban, especially younger workers who live away from home and engage in less farm work, increasingly dominate the off-farm employment [2]. This would lead to a young generation of rural residents living off the farm and knowing much less about farming than their predecessors.

Referring the rural-urban labor mobility in China, we must stress the unique character of Chinese economic structure adjustment, namely the hukou System (household registration system) which has been considered as the root because of social exclusion of rural-urban migrants in China [3, 4].

Chinese economy has been subject to the transition from a dual economy to a more integrated economy [5]. Rural migrant workers in China, being called nong mingong with agricultural hukou working in cities, are not legally considered as urban workers with non-agricultural hukou, and thereafter are not eligible for the urban welfare and rights that are available to any urban resident [6]. Thus, this dual economy sets rural labors being in an embarrassing position. Another significant character of rural labor is intermittent or seasonal which means rural labor may find jobs in urban regions this year and might stay at home and do farm work next year. Also, rural labors may resort to urban work off the season and come back on farm work in the season within a 
farm year. Such a migrate mode under the specific dual economy keep the opportunity costs of farmers quite low, and consequently makes them easily exploitable [7].

China is a typical developing country. The migration situation is the same as that shown by Lewis Dual Sector Model of Development in 1954. The Model explains how a developing economy moves from a traditional agricultural base to a modern manufacturing led economy on the basis of assuming that a developing economy has a surplus of unproductive labor in the agricultural sector. Those labors would be attracted to the growing manufacturing sector in urban regions where higher wages are on offer. Although urbanization is the way to narrow rural and urban family income disparities, concerns over the rapidly urbanization process have emerged recently following a policy debated around the policy effects induced rural-urban migration that is feared to have contributed to employment burden in urban areas and shortage of rural labor. The key question faced by Chinese policy makers is the impacts of the complication of rural-urban shift behavior in variant household income groups. What measures should be put in place to minimize the negative impacts and maximize potential opportunities arising for rural farmers.

Prior studies concentrate on rural labors migrate decision making or migrate behavior ignoring the distinct characteristic of labors in various agri-sectors. Basically, agricultural products can be categorized into cereal crop (i.e., sugarcane, maize (corn), rice, wheat, soybeans, and cotton, etc.) and cash crop (i.e., horticultural crops such as vegetables and fruits) by its economic value. Cash crop is named as High Value Agricultural Products (HVAPs) [8]. Cereal crops are mainly used for food, clothing, and other human uses, whereas HVAPs are grown for sale to return a profit [9]. Most notably, cereal crops can be extensively operated while HVAP needs to be intensively managed. This inherent discrepancy might lead to conversely shift behavior between the two groups and thus would affect the implementation of rural-urban shift policies in the two distinct groups of farmers. An obvious question comes to mind, why don't crop farmers shift to HVAPs? This can be explained by two reasons. Firstly, the initial investment of HVAPs, i.e., buying good seeds, fertilizers, et al., is comparative higher than crop farming. Secondly, apple tree is perennial and it will take at least 3-4 years to yield. It means grower has no benefit from orchard in the first several years but still need to work on it.

Another manifestation of Chinese rural labor market is seasonal. Specifically, rural labor can be classified into full-time and part-time ones in line with the working time on farm; they can also be grouped into self-employed and hired rural labors on the basis of whether managing their own farm land ${ }^{1}$. Deeply, self-employed labors can be broken down into full-time self-employed and part-time self-employed family

1 Self-employed labor is rural resident who lives in rural area, owns and manages farm land and/or orchards; hired labor is rural resident who lives in rural area, searches for farm employment in local labor force market. labor. ${ }^{2}$ Given the distinctions of migrate behavior among those types of rural labors, this research will be with particular emphasis on full time self-employment family labors as they are the dominant labors in rural China.

A number of studies centered in farmers' migrate behavior, but none to our knowledge, have empirical researches on a specific type of farmers. Thus, the case study of apple growers in China has practical implications in HVAPs growers' migrate attitude. The results can be also indications to the sustainable development of HVAPs industry in developing countries.

The aim of the paper is to investigate the influents on HVAPs farmer's migrate decision. The route for the article is as follows. The analytical framework is explored initially. We then report on data and the sampling procedure. The econometric results of the impact factors on HVAPs grower's migrate decision are presented. In the final section, we conclude with a summary of some policy implications of the research.

\section{Analytical Framework and Assumptions}

\subsection{Analytical Framework}

Harris-Todaro model explains issues concerning migration with the assumption that the migration migrate decision is shaped by individual's expectation of income differentials between transferor origins and destinations rather than just wage differentials [10]. That is, farmers' migration behavior associates with the urban-rural real income differential and the probability of obtaining an urban job based on an assumption that any migrant who enters the modern sector is "absorbed" into the gainfully employed at the prevailing urban real wage [11]. Individual grower's urban income expectation is a major variable to evaluate grower's migrate decision. However, the model assumes that potential migrants are risk neutral. This assumption is questionable because poor migrants will likely be risk averse and require a clearly greater expected urban income to migrate. Therefore, the average value is able to approximate individual grower's expected urban income instead of the data directly obtained from questionnaire ${ }^{3}$.

The family income of rural household (FI), and the mobility

2 Combine with our field survey, full-time self-employed family labor is those who lives in rural area, own and manages a farm areas and/or an orchard, and only does on-farm activities (equal/more than 7 months); Part-time self-employed family labor is those who might live in rural area, and does farm activities during on the season; or who does not live in rural area, comes back home to help family working on farm activities on the season (less than 3 months).

3 In the questionnaire, three questions are asked for the purpose of obtaining the data of individual grower's expected urban income. How much is your daily expected urban income? If you had working experience in urban region, what was the daily income? If you don't have working experience in urban region, what was the daily income of your neighbors or relatives with the similar age of you working in urban area? Then, we apply the average number of the expected daily urban income and the real daily income in urban area to represent the adjusted expected urban income. The alteration of individual grower's expected urban income calculation assumes risk aversion instead of risk neutrality. 
cost including transportation cost, living expenses, etc. are important indicators to reflect farmer's migration decision [12]. In this research, FI equals to the total family farm income minus production cost covering fertilizer, chemical pesticide, hired labor, and machinery. It is expected to be negatively responded to grower's attitude-to-migrate.

The opportunity cost, which is usually ignored in farmer's migrate decision-making process, caused by the risk and uncertainty. A few studies consider the shift opportunity cost of rural household resulting from possible adjustments that growers could make in response to potential risks, i.e., growers would prefer farm activity to urban jobs if they think the urban wage would be less than the farm income. The opportunity cost of migration was quite high for farmers in China [13]. Rural-urban shift opportunity cost as the cost of passing up the incomes obtaining from local employment when making the decision of finding jobs outside of the local rural areas [14]. We will follow Li's definition and calculate it with the adjustment of average wage of employed persons in urban units from China Statistics Yearbook $2012^{4}$. Noting that the shift opportunity cost is not regarded as an actual cost in any financial statement, it can be explained as shadow price. The higher the shift opportunity cost is, the less probability farmer transfers, which intuitively make sense.

Scholars address that farmer's age has positive effect on farmer's transfer decision [15]. What we should pay attention to is that although the primary data of apple growers are defined at farm household level, for the young members in a farm household, their migration attitude cannot be explained as the rural-urban migration attitude. According to our face-to-face interview and the descriptive statistics of the primary data, all the young members less than 30 years with high school or university educational background prefer urban jobs. Thus, the migration attitude of the rural young generation could be different from their parents and grandparents. We particularly target on the migration attitude of rural farmers over 30 years.

With respect to education, there was no consistent conclusions affirming the impact sign on rural-labor migration. Farmers with less education attainment shows a higher probability to migrate; whereas other researchers argue that educational level positively affect migrate willingness [17]. Thus, the impact sign is uncertain.

It is reasonable that growers with rich urban working experiences may have greater probability to migrate [12]. Involving farm size, we assume that grower with larger orchard would have lower probability to migrate, partially attribute to the scale efficiency and the higher shift

\footnotetext{
4 The daily shift opportunity cost of a full-time self-employment grower (OPP) is calculated:$$
O P P=\frac{A I N}{D F L}-A W E \text {, }
$$

Where $A I N$ is the total family apple income, $D F L$ is the working days of a full-time self-employment grower in a year, $A W E$ is the average wage of employed persons in urban units. Note that the data of $A I N$ and $D F L$ are directly obtained from the field survey, the data of $A W E$ is from China Statistics Yearbook 2012.
}

opportunity cost. In terms of grower's farm experience, neither literature nor the field discussion shows an indication. Thus, the expected sign is uncertain.

Three items are applied to characterize the infrastructure construction concerning road condition and telecommunication constructions. It can be assumed that the direction of the three variables would be negative. In other words, better rural infrastructure constructions would be helpful to keep growers staying in rural regions.

Agricultural subsidies might also influence grower's migrate attitude. Still little references show the impact sign of these factors. The expected sign are thus uncertain.

Overall, the influents on HVAPs grower's migrate attitude mainly cover four modules. 1) variables of the expected wage in urban area, net family farm income, and shift opportunity cost; 2) indicators of personal characteristics covering age, years of schooling, years of farm experience, apple farm size, as well as gender and urban working experience dummies; 3) grower's evaluation on road condition, irrigation facilities, and telecommunication constructions, as reflected the rural infrastructure constructions; 4) grower's evaluation on agricultural loan and agricultural subsidy.

\subsection{Assumptions}

The validity of the study rests on four vital assumptions.

$\mathrm{H}_{1}$ : apple growers don't shift to urban jobs in response to higher apple income.

$\mathrm{H}_{2}$ : apple income of farm household is equal to his family farm income. Approximately all the surveyed growers report that apple income accounts for over $90 \%$ of their family income, thus the study is without regard to incomes from other channels.

$\mathrm{H}_{3}$ : apple growers are interested in urban jobs for possible better salary, and simultaneously they can find labor-intensive jobs in urban areas.

$\mathrm{H}_{4}$ : the income differences between daily apple income and the average wage of employed persons in urban units represent the shift opportunity cost of a full-time self-employed grower.

\section{Data and Methods}

\subsection{Sampling Procedure}

China has becoming the largest fresh apple producer worldwide since 2012 (USDA-ERS). Shaanxi produces over half the Nation's domestically grown apples and has been the leading apple-growing Province since 2009 (CARS-AIR) [18]. The shift decision of apple growers in Shaanxi is a good case study in consideration of its large apple acreage and apple production. The research recommendation would be as a representative employed by HVAPs producers in China.

Systematic sampling method is employed to choose the county-level samples from an ordered sampling frame. Dropping respondents with failures to recall the information in the questionnaire, 365 of the observed apple growers provide usable data. Note that no rural household has shifted 
to other business in and before the survey year in the sample dataset.

Standard questionnaires combined with face-to-face interviews are used to gather detailed information. The questionnaire covers topics ranging from farm household demographics, farm characteristics, attitude toward agricultural policies, rural infrastructure constructions, etc. For the purpose of the research we used the survey data to generate: fresh apple sales and off-farm wage employment income for the income comparison; variables referring to attitude towards agricultural policies used in the estimation of rural-urban. In addition to survey data, we used information on the average wage of employed persons in urban units from China Statistics Yearbook 2012 to generate the individual grower's shift opportunity cost in the model.

\subsection{Methods}

A multicollinearity is used to alleviate the problem of high correlations between explanatory variables which we are interested in. Probit analysis is employed to estimate the determinants on growers' migration decision.

\subsubsection{Multicollineartiy}

Multicollinearity is used to describe the problem when an approximate linear relationship among the explanatory variables leads to unreliable regression estimates [19]. In the field survey questionnaire, we designed questions as whether is a member in cooperatives, whether expects the urban life? the evaluation of the educational infrastructure construction and welfare in rural area? The use of too many dummy variables is the typical cause for multicollinearity. Technically, two solutions can be done to alleviate the multicollinearity problem. One is to omit one or more variables from the model; the other is to extend the sample size [19]. Typically, enlarging the sample size is not practical We are thus to estimate the sample correlation coefficient among all explanatory variables, and then excluding variables which the correlation coefficients are above 0.3 from the model to alleviate.

\subsubsection{Probit Model}

Probit model is a type of regression where the dependent variable $Y$ can only take two values, "1" and " 0 ". This study uses farm household survey data, $Y^{*}$ is a latent variable defined as 1 if full-time self-employed family labor is willing to migrate to urban jobs and 0 otherwise, the distribution of $\mathcal{E}$ is a standard normal density, $Y$ is an indicator for whether $Y^{*}$ is positive:

$$
\begin{gathered}
Y^{*}=X^{\prime} \beta+\varepsilon, \quad \varepsilon \sim N(0,1) \\
Y=1_{\left\{Y^{*}>0\right\}}=\left\{\begin{array}{l}
1 \text { if } \mathrm{Y}^{*}>0,-\varepsilon<\mathrm{X}^{\prime} \beta \\
0 \text { otherwise. }
\end{array}\right.
\end{gathered}
$$

The detailed information of the estimation variables is summarized in Table 1.

\begin{tabular}{|c|c|c|}
\hline Items & $\begin{array}{l}\text { Variable } \\
\text { name }\end{array}$ & Variable scale \\
\hline \multicolumn{3}{|l|}{ Dependent variable } \\
\hline Migrate decision & TRF & $\begin{array}{l}1=\text { willing to migrate } \\
0=\text { unwilling to migrate }\end{array}$ \\
\hline \multicolumn{3}{|l|}{ Independent variable } \\
\hline $\begin{array}{l}\text { Adjusted expected } \\
\text { urban wage }\end{array}$ & AEP & Yuan/day \\
\hline Net apple income & NET & Thousand yuan/year \\
\hline Shift opportunity cost & OPP & Yuan/day \\
\hline \multicolumn{3}{|c|}{ Grower demographics and farm characteristics } \\
\hline Age & AGE & Years \\
\hline Years of schooling & EDU & Years \\
\hline Farm experience & FEP & Years \\
\hline $\begin{array}{l}\text { Urban working } \\
\text { experience }\end{array}$ & UWE & $\begin{array}{l}1=\text { have urban working experience } \\
0=\text { otherwise }\end{array}$ \\
\hline Apple farm size & ASZ & $\mathrm{Mu}^{\mathrm{a}}$ \\
\hline \multicolumn{3}{|c|}{ Infrastructure construction evaluation } \\
\hline Rural road condition & $\mathrm{RCO}$ & $1=$ very bad $2=$ bad $3=$ moderately \\
\hline Telecommunication & TEL & $4=$ good $5=$ very good \\
\hline \multicolumn{3}{|l|}{ Agricultural policy } \\
\hline $\begin{array}{l}\text { Convenience of } \\
\text { agri-loan }\end{array}$ & AGL & $\begin{array}{l}1=\text { very bad } 2=\text { bad } 3=\text { moderately } \\
4=\text { good } 5=\text { very good }\end{array}$ \\
\hline Agricultural subsidy & AGS & Yuan/year \\
\hline
\end{tabular}

Table 1. Variable descriptions.

Note: ${ }^{\mathrm{a}} 1 \mathrm{mu}=0.0667$ hectare.

Table 2. Summary of statistical description (UT=unwilling-to-migrate;

\begin{tabular}{|c|c|c|c|c|c|}
\hline \multirow[t]{2}{*}{ Items } & \multicolumn{2}{|l|}{ Mean } & \multicolumn{2}{|c|}{ Std. Dev. } & \multirow{2}{*}{ P-Value } \\
\hline & $\mathbf{U T}$ & WT & $\mathbf{U T}$ & WT & \\
\hline $\begin{array}{l}\text { Adjusted expected urban } \\
\text { wage }\end{array}$ & 74.4 & 92.4 & $33.2^{*}$ & $30.6^{*}$ & 0 \\
\hline Net family apple income & 38.9 & 17.7 & $55.8^{*}$ & $19.4^{*}$ & 0 \\
\hline Shift opportunity cost & 57.5 & -36.6 & $-116.1^{*}$ & $24.9^{*}$ & 0 \\
\hline Age & 53.0 & 55.0 & $8.2^{*}$ & $8.8^{*}$ & 0.02 \\
\hline Years of schooling & 8.4 & 7.5 & $2.8^{*}$ & $2.1^{*}$ & 0.00 \\
\hline Farm experience & 18.0 & 17.1 & 4.8 & 4.7 & 0.05 \\
\hline Urban working experience & 0.2 & 0.1 & 0.4 & 0.6 & 0.42 \\
\hline Apple farm size & 4.1 & 2.6 & 2.3 & 1.2 & 0 \\
\hline Rural road condition & 3.3 & 3.6 & $1.2^{*}$ & $1.2^{*}$ & 0.02 \\
\hline Telecommunication & 3.5 & 3.0 & $1.2^{*}$ & $1.2^{*}$ & 0 \\
\hline Convenience of agri-loan & 2.3 & 2.5 & 1.1 & 1.2 & 0.09 \\
\hline Agricultural subsidy & 280.5 & 249.2 & 184.7 & 115.1 & 0.05 \\
\hline
\end{tabular}
WT=willing-to- migrate)

Note: * Differences between UT and WT are statistically significant at $p=0.05$.

\section{Results and Discussions}

Summary statistics of probit model's variables are shown in Table 2. The differences in the adjusted expected urban wage, net family farm income, and the shift opportunity cost 
between WT and UT growers are statistically significant. The results can be translated into that grower with lower expectation on urban wage, greater apple income, and higher shift opportunity cost, has weaker shift willingness. In comparison, the expected urban wage of WT growers is 92.4 yuan/day, whereas it is74.4 yuan/day of UT ones. This difference is a reflection of a more attractive wage labor market in urban regions. Similarly, the negative shift opportunity cost of WT growers (-36.6 yuan/day) reflect a relatively lower family farm income compared with UT ones.

The age of a WT grower is 55 years being on average 2 years older than those UW ones. With respect to education, the UW growers have on average one additional year of schooling. The results mean that older grower with less years of schooling is more likely to migrate. Although scholars hold different states on the relationship between farmer's migrate behavior and educational background, the result in our case is consist with the point that rural labors in China with poor educational background show strong transferring willingness [5].

Variable of apple farm size shows statistically significant differences between the considered groups. It suggests that grower with large orchard to manage shows weak migrate willingness. Among the attitudes toward infrastructure construction involving road condition and the telecommunication constructions (i.e., availability to the high-speed internet), the differences are statistically significant too.

Table 3 depicts the results which the factors affecting HVAPs grower's migration decision by the Probit model. 7 coefficients are significant and illustrate the expected sign among 12 variables. The marginal effect for explanatory variables are also computed employing Stata 7.

Table 3. Regression results.

\begin{tabular}{llll}
\hline Variable & Coefficient & z-Statistic & $\mathbf{d y} / \mathbf{d x} \mathbf{a}^{\mathbf{a}}$ \\
\hline Adjusted expected urban wage & 0.0045 & 1.07 & 0.0015 \\
Net apple income & $-0.9711^{* * *}$ & -5.27 & -0.0000 \\
Shift opportunity cost & $-0.0216^{* * *}$ & -5.69 & -0.0075 \\
Age & -0.0019 & -0.14 & -0.0006 \\
Years of schooling & $-0.0895^{* *}$ & -2.09 & -0.0308 \\
Farm experience & $-0.0372^{*}$ & -1.73 & -0.0125 \\
Urban working experience & 0.1605 & 0.48 & 0.0569 \\
Apple farm size & $-0.2287^{* * *}$ & -2.93 & -0.0788 \\
Rural road condition & -0.0096 & -0.12 & -0.0033 \\
Telecommunication & $-0.1467^{*}$ & -1.71 & -0.0492 \\
Convenience of agri-loan & 0.1285 & 1.39 & 0.0431 \\
Agricultural subsidy & $-0.0014^{*}$ & -1.80 & -0.0005 \\
Constant & 0.7066 & 0.63 & \\
\hline
\end{tabular}

Note: $*$ significant at $\mathrm{p}=0.10 ; * *$ significant at $\mathrm{p}=0.05 ; * *$ significant at $\mathrm{p}=$ 0.01 .

${ }^{\mathrm{a}} \mathrm{dy} / \mathrm{dx}$ is for discrete change of dummy variable from 0 to 1 .

The empirical results demonstrate that the probability of migration declines with the net family farm income (NET) and shift opportunity cost (OPP). The findings can be confirmed by the descriptive statistics in Table 2 . The mean value of NET for UT grower is about 38.9 thousand yuan, compared with only 17.7 thousand yuan for WT ones; the shift opportunity cost for UT grower is 57.5 yuan, compared to -36.6 yuan for WT ones. These can straightforwardly interpret the result that higher family farm income and shift opportunity cost attribute to the lower probability of migrate willingness.

The adjusted expected urban wage (AEP) has a positive sign but statistically insignificant impact in the model. One interpretation is that we recalculated the expected urban wage to avoid risk neutral assumption. The adjusted expected urban wage is apparently lower than the expected urban wage answered by grower directly obtained from questionnaire. The increasingly higher payment for hiring a HVAPs labor in the season, especially male labors with pruning skills, may be another reason. Instead of blindly finding a job in urban region, grower's rational judgment on urban work might also be the reason of insignificant impact.

Considering the socio-demographic household characteristics, the migrate willingness significantly decreases with the schooling years and farming experience of the household head. The more years of schooling and the richer farm experiences, the less likely growers migrate out to find employment. The regression result of EDU is similar with the findings that farmers with lower educational attainment have higher probability to migrate [16]. Concerning FEP, HVAPs growing activity needs long time experiences in pruning, packaging, etc. Combining with the face-to-face interview, growers with rich apple planting experience prefer not migrate to urban jobs as they already get used to the farming lifestyle. Interestingly, variable indicating urban working experience shows insignificant influence on grower's migration decision. Possible explanation is that having an urban job does not seem to guarantee a high income. Variable indicating the management size of apple orchard (AFS) has marginally and negatively significant influence on growers' migrate decision. It is not surprising given that large management size means higher apple income. As expected, the larger apple farm size is, the less probability of grower transferring to urban jobs. Statistical data in Table 2 also verifies the finding that apple farm size for UT growers is averagely $4.1 \mathrm{mu}$ compared with $2.6 \mathrm{mu}$ for WT ones.

One variable, rating on telecommunication (TEL) reports a statistically negative connection with grower's migrate willingness. The marginal effects of TEL after probit is estimated to be negative $(-0.1467)$. It can be translated into that a unit decrease of grower's evaluation on rural telecommunication construction will lead to a unit increase of probability of grower's migrate willingness by 4.92 percent. In consistent with our expectation, grower values the telecommunication construction at greater level correspond to a lower migrate probability.

Grower values the agricultural subsidy (SUB) at greater level correspond to a lower migrate probability. Whereas growers' rating on the convenience of applying agricultural 
loan (LOA) has positive sign but statistically insignificant. The main reason leading to insignificant impact is the weak loaning behavior of growers. In combination with the rural household survey results, 80.8 percent respondents are unwilling to apply for loan from local Rural Credit Cooperatives which are identified as a key vehicle for the delivery of financial services to the rural small-scale entrepreneur/farmers. They complaint the complicated loan application procedures and the higher requirement of mortgage. Another reason is certainly due to that the primary purposes of growers' applying for agricultural loan are for children education (particularly the college education tuition) and building the house which are apparently not related to farm activities.

\section{Conclusions}

The paper investigates determinants on rural households' migrate attitude taking HVAP growers in China as an example. Empirical evidence reveals that great net family farm income and shift opportunity cost, rich farm experience and large farm size mitigate growers' migrate decision, whereas poor infrastructure constructions and lack of agricultural subsidy increase grower's willingness-to-migrate. Further, the relatively higher shift opportunity cost of HVAP growers implies that growers should keep their HVAPs business instead of looking for the working opportunities in urban regions.

In general, larger farm land, improved planting techniques, better rural infrastructures, and greater agricultural subsidies will allow HVAPs growers to achieve higher levels of farm income and better living conditions, and thus to alleviate HVAP labor shortage issue in season. The investment in the local construction of telecommunication system, particularly the high-speed internet facilities plays a dominant role in keeping HVAPs growers working on farm work as the price of HVAPs highly depends on market prices.

Four policy recommendations are summarized for the HVAPs grower's migrate situation in China: 1) enlarging the family farmland holdings in the way of Land Transfer; 2) targeting the extension training at the older growers; 3) improving the telecommunication conditions in rural regions; 4) putting forward specific agricultural subsidy policies. This should be practiced on three levels. That is, subsidies directly on the use of bio-pesticide and organic fertilizer to encourage safety products produce, on agricultural issuance to reduce the loss caused by natural disasters, as well as on agricultural loan for buying fertilizers, importing new apple varieties, et al.

\section{Acknowledgement}

The research is based upon work supported by the China Agriculture Research System under Grant No. CARS-28, the Fundamental Research Funds for the Central Universities under Grant No. 1zujbky-2015-39, and Program for Changjiang Scholars and Innovative Research Team in University under Grant No.IRT13019.

\section{References}

[1] Li, M, et al. 2009. Rural Labor Migration in China. Report (09-7), Samsung Economic Research Institute.

[2] De Brauw, A., Huang, J., Rozelle, S., Zhang, L., \& Zhang, Y. 2002. China's Rural Labor Markets. The China Business Review, 3-4.

[3] Han, D. 2010. China's Workers Are Stirring. The New York Times, June 17, 2010. [www.nytimes.com/2010/06/17/opinion/17iht-edhan.html], accessed June 18, 2010.

[4] Huang, Y., Guo, F., \& Tang, Y. 2010. Hukou status and social exclusion of rural-urban migrants in transitional China. Journal of Asian Public Policy, 3(2), 172-185.

[5] Cai, Fang, Du. Yang, Wang, Meiyan. 2001. The New Stage of Population Migration and the Characteristics of Human Resources. Population Science of China. 2,19-24.

[6] Chen, L., X. Zeng, and Y. Yumei. 2011. Rural Labor Absorption Efficiency in Urban Areas Under Different Urbanization Patterns and Industrial Structures: The Case of China. IZA Discussion Paper No. 6189.

[7] Kelly, D. 2008. Reincorporating the Mingong: Dilemmas of Citizen Status. Migration and social protection in China, 14, 17.

[8] Weinberger, Katinka, and Thomas A. Lumpkin. 2007. Diversification into Horticulture and Poverty Reduction: A Research Agenda. World Development, 35(8), 1464-1480.

[9] Temu, Andrew E., and Anna A. Temu. 2005. High value agricultural products for smallholder markets in Sub-Saharan Africa: Trends, Opportunities and Research Priorities." In Prepared for an international workshop, "How Can the Poor Benefit from the Growing Markets for High Value Agricultural Products, pp. 3-5.

[10] Harris, John R. and Todaro, Michael P. 1970. Migration, Unemployment and Development: A Two-Sector Analysis, American Economic Review, 60 (1): 126-142.

[11] Todaro, Michael P. 1969. A model of labor migration and urban unemployment in less developed countries. The American Economic Review, 138-148.

[12] Sheng, Laiyun. 2007. Analysis of the Determinants of Rural Labor Migration in China. China Rural Survey. 3, 2-15.

[13] Zhao, zhong. 2005. Migration, Labor Market Flexibility, and Wage Determination in China: A Review. The Developing Economies 2, 285-312.

[14] Li, D. 2004. Economic Analysis of Rural Labor Migration. Master diss., Henan Agricultural University, Henan, China.

[15] Roberts, K. D. 1997. China's" tidal wave" of migrant labor: what can we learn from Mexican undocumented migration to the United States? International Migration Review, 249-293.

[16] Xu, Peiqing. 2003. Rural Labor Transfer Issues. Xue Hai. 5, 54-57.

[17] Rozelle, S., Alan de Brauw, J. Huang, L. Zhang, Y. Zhang. 2003. The Evolution of China's Rural Labor Markets during the Reforms. Department of Agricultural and Resource Economics, University of California, Davis, CA. 
[18] Apple Industry Research Report, 2012. China Agricultural Research System. Ministry of Agriculture of People's Republic of China.

\section{Biography}

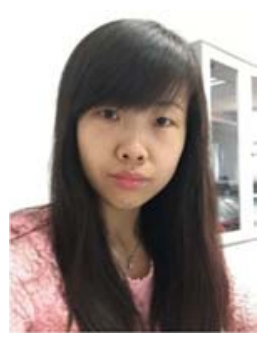

\section{Lijia Wang}

Lijia Wang is an instructor. She works at State Key Laboratory of Grassland Agro-ecosystems, Department of Pastoral Agriculture Science and Technology, Lanzhou University. She has published several articles in academic journals such as Food Control, China Agricultural Economic Reviews, and Annals of Public and Cooperative Economics, etc.
[19] Verbeek Marno. 2000. A Guide to Modern Econometrics. Baffins Lane, Chichester, West Sussex PO191UD, England.

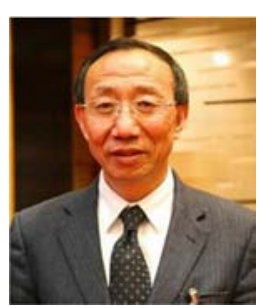

\section{Xuexi Huo}

Xuexi Huo is a professor. He works at Department of Economics and Management, Northwest A\&F University. He has published several articles in academic journals such as Food Control, China Agricultural Economic Reviews, Journal of Food, Agriculture \& Environment, International Journal of Economics and Finance, etc. 